\title{
La historiografía musical como producción activa de ausencias Para una historia popular de la música ${ }^{1}$
}

\author{
Music historiography as active \\ production of absence \\ Towards a popular history of music
}

Martín Eckmeyer ${ }^{2}$ Universidad Nacional de La Plata martineckmeyer@gmail.com 


\section{Resumo}

La historiografía musical afirmativa, conformada básicamente por la musicología y el folklore, ha producido como inexistente la dimensión histórica de la música popular, mediante la propia aplicación de una epistemología objetual/personalista basada en la concepción occidentalocéntrica de la música como objeto (de cambio). Si bien esta es una historiografía zombie, a todas luces vetusta, sigue habitando la porción mayoritaria de los imaginarios sobre la música, y en especial, está presente en los cursos universitarios de historia de la música. Este trabajo intentará problematizar esta concepción hegemónica con el fin de contribuir a la (re)integración conceptual, en una historia popular de la música, de las prácticas del mundo popular subalterno presentes en todo el desarrollo histórico de Occidente y en especial, de Latinoamérica. Dado que para ello es necesaria una aproximación conceptual divergente, propondremos una serie de conceptos-otros que puedan dar cuenta de la especificidad musical del mundo popular subalterno: su aspecto localizado y performativo, su condición dinámica de musicar, y su carácter nómada, mestizo, transcultural y transmoderno.

Palabras clave: Historiografía de la música - Música popular - Musicología histórica - Folklore - Estudios de Música Popular

\section{Abstract}

Affirmative musical historiography, in essence shaped by musicology and folklore, has produced as non-existent the historical dimension of popular music, through the application of an objectual-personalistic epistemology based on a western-centered objectified conception of music. Although this is a zombie historiography, clearly outdated, it still inhabits the majority portion of the social imagery about music, especially present in undergraduate courses of music history. This paper problematizes this hegemonic conception, in order to achieve a (re) integration of practices from the popular subaltern world, that exists in the whole development of Western and especially Latin American history. This task will require a divergent framework through alternative concepts that can understand the peculiar features of musics in popular subaltern world: the localized, performative and dynamic attributes of musicking, through its nomadic, mestizo, transcultural and transmodern features.

Keywords: Music historiography Popular Music - Historical musicology Folklore - Popular Music Studies.

El presente trabajo sintetiza de modo muy general y panorámico los planteos contenidos en la tesis doctoral "Viejos sonidos subalternos", producida entre los años 2019 y 2020 en el marco de una beca del Consejo Interuniversitario Nacional de Argentina. En ella se desarrolla en extenso la crítica historiográfica aquí presentada y se aplican los conceptos propuestos al análisis de una serie diversa de casos musicales.

Profesor Titular Historia de la Música I, Instituto de Investigación en Producción y Enseñanza del Arte Argentino y Latinoamericano. Facultad de Artes - Facultad de Artes. Universidad Nacional de La Plata | Profesor Titular Historia Social y Política de las Músicas Latinoamericanas y Argentinas, Facultad de Humanidades, Artes y Ciencias Sociales. Universidad Autónoma de Entre Ríos. 
Tenemos la certeza de que el canto llano se anotó y, que por ende, se conservó de una manera bastante completa, pero si tuviéramos un conocimiento igualmente completo acerca de la música profana de los siglos $\mathrm{VI}$ a XI, ¿la hallaríamos igualmente interesante?

GROUT, [1973] 1980, p. 80.

Como sabemos, la música popular no ha formado parte, y todavía no lo hace, del relato mainstream de la historia de la música. Más allá de la enorme cantidad de publicaciones, libros y estudios académicos sobre música popular -que terminarán superando en número a los dedicados a la música "culta"³- en lo que hace a historia de la música todavía tiene vigencia la denuncia aparecida en el número 1 de la revista Popular Music (MIDDLETON Y HORN, 1981, pp. 1-2), sobre el carácter muy marginal de su presencia. Lo que significaba reparar en su atronadora ausencia. Es que, como nos han advertido en numerosas ocasiones (KERMAN, 1985; COOK, 2001; SMALL, 1999) la musicología histórica orientó sus estudios construyendo categorías de estilo, sobre el papel y escindiendo lo intelectual de lo performático. El Atlas de la Música de Ulrich Michels, un libro que circula en la academia muchísimo más de lo que su antigüedad y la prudencia aconsejan, dice:

La idea intelectual convierte el material acústico en arte de los sonidos. Con el intelecto la música adquiere historia. Esto vale en especial para la música polifónica de Occidente desde el siglo XII, y menos para ciertas prácticas populares y para gran parte de la música extraeuropea. En este sentido la historia de la música es, en cierto modo, autónoma: es una historia de la técnica de la composición, de las formas, de los estilos, de los géneros, etc." (1992, p. 11).

Tomando como modelo a la música tonal decimonónica -que resume buena parte de lo que aparece en la cita- la musicología histórica procedía a evaluar, hacia atrás y hacia adelante en el tiempo, qué músicas valdría la pena incorporar a su relato en función de sus reglas internas (DAHLHAUS, 1997). Así se constituyó un modelo epistemológico deudor del positivismo (KERMAN, 1985; BERMÚDEZ, 1982; PÉREZ GONZÁLEZ, 2010), que está basado en una concepción objetual (GOEHR, 1992; ATTALI, 2011, SMALL, 1999), cuyo sentido descansa en la personalidad del autor (COOK, 2001). Bajo esta concepción, la historia de la música debe (STANLEY, 2001) agruparse según los cambios en el estilo de composición, por medio del estudio de su lógica interna y autónoma (DAHLHAUS, 1997; SHREFFLER, 2003). Por lo tanto, sólo será posible estudiar las músicas discernibles a través del cotejo analítico de cualidades tales como la complejidad

\footnotetext{
3 En este texto utilizaremos la categoría "música culta" para referirnos a un repertorio que suele ser categorizado con otros términos igualmente problemáticos y polémicos: "clásica", "seria", "erudita", "académica", "de tradición escrita", etc. Nuestra elección se basa en su raíz socio histórica por rechazo de las formas sonoras del pueblo, constituyendo un acto primigenio de estratificación que pretendió arrogarse la única forma posible de cultura dentro de occidente. Como se verá en el desarrollo del texto, esta intención segregacionista y apropiadora permanece en la definición de folklore (que es no-música) e incluso de "música popular", que necesita del adjetivo a pesar de ser mayoritaria y "común", a diferencia de la música "culta", que sí puede todavía permitirse ser enunciada simplemente como "música" en los títulos de libros, cursos y programas de "historia de la música", que nunca añaden un "elitista, occidentalocéntrica, blanca y cisheteropatriarcal", aún cuando deberían hacerlo. En adelante, no colocaremos más comillas al término, ya que buena parte de nuestro argumento descansa en que todavía debemos esperar a que los gestos dominocentristas de la historiografía musical se revelen evidentes para el sentido común académico. Momento en el que sí será necesario colocar nuevamente las comillas. No perdemos la esperanza de que pronto así será.
} 
armónica, la coherencia formal o la homogeneidad y cohesión de los materiales musicales. El vehículo último de todo este proceso se encuentra en la partitura, que simultáneamente se erige con exclusividad como registro de las intenciones del compositor, material de análisis estructural y fuente histórica (COOK, 2001). Este proceso tiende irremediablemente a la reificación e introduce un sesgo musicológico muy importante que podemos denominar "centrismo notacional" (MIDDLETON, 1990, p. 105)

De este modo, la anomalía dentro del pluriverso musical global, que es la escritura en partitura, adquiere mediante la musicología el estatuto de creación, y finalmente reemplaza la definición misma de música. O de lo que esperamos que la música sea. Pero además, al obscurecer esta metonimia, la disponibilidad de partituras se transformó, mutatis mutandi, en disponibilidad de fuentes escritas históricas válidas. De modo tal que la composición escrita e individual de la música no sólo se convierte en rasgo universal, natural de la música, sino que sólo podrá historizarse aquello que se corresponda con esas coordenadas.

Estos aspectos no tienen nada de técnicos, son fundamentalmente estéticos e ideológicos. Han servido para ocultar la voluntad de la musicología por desentenderse del estudio de músicas producidas bajo otros procedimientos e ideas, generando al mismo tiempo comparaciones que siempre han desestimado a las otras músicas. Manifestaciones que denominaremos aquí en base a la categoría del Mundo Popular Subalterno en la cual se incluyen

los pueblos coloniales y semicoloniales, y del proletariado obrero y campesino de las naciones hegemónicas [sector que es] directamente afectado por el carácter fundamental de una sociedad fundada en la división en clases, y que toca de lleno los motivos de la explotación y del predominio (DE MARTINO, 2008, p. 77).

Es decir que el mundo popular subalterno, que no es una mera clase, una etnia o un grupo lingüístico/cultural específico, es un colectivo transcultural y mestizo definido en contraste con los sectores dominantes y la estratificación social que éstos proponen, desplegada a partir de fuerzas como la explotación, la opresión racial y/o el colonialismo. Denominación afín a otras como "bloque social de los oprimidos y excluidos" (DUSSEL, 2006, p. 92), o nociones como Sur Global (SANTOS, 2014), que incluyen tanto a sectores mayoritarios como a minorías excluidas de una participación social efectiva, y a pueblos racializados por la modernidad y etnologizados por la posmodernidad (como afroamericanos o indígenas) que se hacen populares cuando son subalternizados "ingresando en la condición que aquí consideramos definitoria de lo popular" (ESCOBAR, 1991, p. 88).

Las músicas del mundo popular subalterno -todas sus músicas- quedan oficialmente al margen de la historia por cuestiones presuntamente metodológicas, que si no existieran habría que inventarlas. Porque como puede leerse en la cita de Donald Grout de nuestro epígrafie, la valoración estética se sobreimprime como criterio historiográfico, permitiendo así expulsar esas otras músicas de la historia y hasta de la cultura, ya que sus practicantes "incultos [son] cantores de canciones de otros hombres" (HOPPIN, 2000 , p. 280). De esta forma toda música que no coincida con un triple carácter objetual-personalista, proveniente de la circularidad y las intrincadas implicancias del genio, 
la obra y la partitura, sólo posible en la música culta de la modernidad occidental, no podrá, por su propia naturaleza, integrarse jamás a la historia.

Definir tácitamente el sentido de qué es historia para el caso de la música, permite convertir la parte en el todo y universalizar los sonidos de las minorías de la minoría. Vale decir, producir hegemonía. Aún cuando nuestra percepción más elemental y primaria constate todo el tiempo que la música consiste fundamentalmente en una articulación temporal del espacio acústico y, por lo tanto, un fenómeno efímero antes que un objeto inmutable, la historiografía de la música ha negado doblemente el carácter performativo, desarrollando un relato escrito de los escritos musicales/partituras. Doble producción de ausencias: la de las músicas que no ingresan a la historia y la de los sonidos de las que sí lo hacen. Metodología, ideología y hegemonía se articulan así de un modo perversamente eficaz. $Y$ las ausencias del relato histórico musical se revelan como producción activa de inexistencias (SANTOS, 2018).

Esta producción activa también incluye el proceso por el cual todas aquellas músicas que no tenían lugar en el paradigma musicológico "caen en la esfera del folclor"4, de tal suerte que los estudios del folklore y luego de la "musicología comparada" -que compara siempre en desventaja (PARASKEVAÍDIS, 1999)- se ocuparon muy bien de aclarar que sus objetos de estudio no eran los antecesores de las músicas del aquí y ahora. Herder escribió que «el pueblo no es la turba de las calles, que nunca compone o canta, sólo chillan y destruyen ${ }^{5}$. Distinción ideológica que neutraliza para siempre la ambigüedad lingüística entre Volk y Pöbel, conservando una subalternidad mítica e idealizada en estado natural y fundamentalmente sumiso ${ }^{6}$, enfrentada con las manifestaciones y expresiones de las masas urbanas, que por las épocas de Herder y los primeros musicólogos se hacinaban de modo infrahumano en las ciudades del pujante capitalismo industrial. Trabajadores que pronto comenzarán a organizarse.

Encontrar que algunos nombres ilustres entre los investigadores revistan tanto entre folkloristas como entre musicólogos, no sólo habla de esa coincidencia de clase social que menciona Burke. Así, el corpus disciplinar derivado por la musicología histórica es distinto del folklore por convencimiento de sus practicantes, que siempre consideraron que ambos repertorios eran cosas bien diferenciadas: uno era música y el otro no, y así aparece en sus esquemas clasificatorios ${ }^{7}$. Lo cual resulta absolutamente funcional hacia -o a consecuencia de- las necesidades clasificatorias del mercado musical que se consolida en la cultura burguesa del siglo XIX.

Podríamos hablar hasta de personificaciones duales que asumen estos investigadores: la del musicólogo o la del folklorista. Los primeros en general no consideraban

\footnotetext{
$4 \quad$ Entrada "música" del diccionario enciclopédico VOX.

5 «Volk heisst nicht der Pöbel auf den Gassen, der singt und dichtet niemals, sondern schreit und verstümmelt» (HERDER, 1967, p. 323).

$6 \quad$ «... el pueblo era un misterio. Algo que describían en términos de todo aquello que sus descubridores no eran (o pensaban ellos que no eran): el pueblo era natural, sencillo, iletrado, instintivo, irracional, anclado en la tradición y en la propia tierra, y carente de cualquier sentido de individualidad (lo individual se había perdido en lo colectivo)» (BURKE, 2014, 43).

$7 \quad$ Para el caso local los nombres de Carlos Vega, Lauro Ayestarán y hasta Mario de Andrade sirven tanto de ejemplo como los de Charles Hubert Parry o Waldo Selden Prat para el mundo angloparlante.
} 
importante declarar su condición de clase, situación que produjo la naturalización de tal identificación; por esta razón es muy raro encontrar datos vinculados a la situación social de la música culta en sus estudios. Los segundos, en cambio, debían declarar la distancia; al no identificarse con el "pueblo" objeto de sus estudios, consideraban un auténtico safari sus paseos etnográficos.

La mayoría de ellos pertenecían a las clases dirigentes [...] Para algunos especialmente a finales del siglo XVIII, el pueblo era interesante desde el punto de vista de lo exótico. Por ejemplo, recorriendo las islas de Escocia en búsqueda de los vestigios de la vida pastoril [el folklorista] Boswell indica al doctor Johnson que «era exactamente como encontrarse una tribu de indios», ya que sus pobladores «tenían una apariencia tan negra y salvaje como la que mostraban los indígenas americanos» (BURKE, 2014, pp. 42-43)

La mancomunidad de folkloristas y musicólogos, que también eran críticos y editores de ambos repertorios, sumada luego a la de los primeros productores fonográficos, hace que deban ser considerados como una totalidad, compleja pero articulada, en la cual lo que por un lado se vislumbra como afán de generación de categorías conceptuales, resulta ser, en su contracara, función racionalizadora para producir criterios de producción comercial y consumo estandarizados de la(s) música(s). En este sentido, son muy sugestivas ciertas simultaneidades: la generación del código armónico tonal en conjunción con los dispositivos de comercialización escénica de la música culta, que resultan en los términos obra-ópera-opus, junto a la afirmación de la personalidad artística, casualmente constituyen luego la base de la musicología estilística. Resumiendo las posturas de Jacques Attali, podemos decir que el compositor, la obra y hasta la inspiración existen cuando todos ellos son puestos a la venta (2011, p. 73). También el auge de la producción de categorías en torno al pretendido pueblo auténtico, permiten la racionalización y objetificación de músicas populares y -una vez comprimidas- su ingreso al mercado: primero en cancioneros folklóricos impresos para uso doméstico y luego con la proliferación de los fonogramas y medios radiofónicos. Estas intenciones clasificatorias de ambas disciplinas están cifradas en sus propios útiles de conocimiento, ocultando sus propósitos de manera muy efectiva, lo que permitió que tanto el folklore como la música culta fuesen preservados de las valoraciones negativas hacia lo comercial, cuando precisamente este procedimiento valorativo diferencial hacía posible su puesta a la venta. Valoraciones negativas que sí recaían en la música ligera que luego llamarían popular. Sí, esa, la de la turba que chilla y grita, entre otras cosas, canciones y danzas ${ }^{8}$.

8

Sabemos de estas clasificaciones, en parte, gracias al valioso trabajo de Derek Scott, que en una actitud pionera ha historizado algunas músicas populares del siglo XIX, sobre todo a partir de 1850. Lamentablemente, este autor no retrocede más en el tiempo, lo cual es comprensible ya que deduce su concepción de lo popular a partir de "lo masivo", asociado con la consolidación del proletariado urbano industrial y en particular, el británico. Por lo tanto no podemos considerar sus escritos como parte de una historia de la música popular en la larga duración. Percepción reforzada en el volumen colectivo compilado por Scott, The Ashgate research companion to popular musicology (SCOTT, 2016), que bien podría ser un ejemplo paradigmático de lo que aquí estamos cuestionando como "presentismo" de los estudios de música popular, ya que en sus más de 570 páginas y 26 artículos, prácticamente todo el abordaje se circunscribe al periodo 1950-2000, reforzando la imagen de que la música popular no tiene historia. Dejando a un lado esta aclaración, referimos como imprescindibles los textos de Scott. Especialmente nos reconocemos deudores de su crítica ideológica a la musicología (SCOTT, 2003) y su agudo análisis de la relación entre la generación de conceptos clasificatorios y las nece- 
De esta suerte las músicas del mundo popular subalterno fueron activamente producidas como inexistentes, silenciadas y omitidas en la investigación, si bien eran audibles y omnipresentes en la vida cotidiana de millones de habitantes en el sur global. Hasta que hace no mucho, en la década de 1980, atestiguamos un vuelco aparentemente sorprendente, cuando emerge el conjunto de los Estudios sobre Música Popular (a partir de aquí PMS por sus siglas en inglés), universo ecléctico y muy vasto (en todo sentido: filosófico, metodológico, ideológico) de investigaciones sobre un repertorio musical (aparentemente) amplísimo ${ }^{9}$. Aunque un rastreo sobre el contenido de los PMS y sus huellas epistemológicas, arroja como resultado un campo bastante más acotado de lo que parece. Como señala Elizabeth Eva Leach, el principal precursor con el que los investigadores de los PMS dialogan y discuten todo el tiempo es Theodor W. Adorno (LEACH, 2009, p. 194). Como este importante autor circunscribió su planteo crítico a la música producida por la industria cultural, dando especial relevancia a los medios técnicos a partir del cambio de siglo entre el XIX y el XX, los investigadores suelen reproducir ese recorte temporal, ya sea que afirmen o rechacen -o ignoren- los postulados teóricos de Adorno. Esta situación, sumada al interés personal que muchos de los investigadores declaran por algunas músicas en particular -como el Rock o el Jazz (JOHNSON, 2018)- hace que los Estudios de Música Popular se concentren en las músicas vinculadas a la fonografía y la radiodifusión, acotando su posible historia a no mucho más que 100 años atrás.

Por supuesto existen muchos trabajos que se han abocado al pasado sonoro más remoto del mundo popular subalterno. En nuestro trabajo tomamos ideas de algunos de ellos, que incluso participan de los PMS, como Marita Fornaro Bordolli, Neil Grosch o el mismo Simon Frith. Además los trabajos de Carmen Bernand, Ana María Ochoa Gautier, Ángel Quintero Rivera o el ya citado Derek Scott, entre muchos otros que no revistan en los PMS, resultan imprescindibles. Lo que pretendemos señalar en el análisis es que la abrumadora mayoría producen un presentismo historiográfico (JOHNSON, 2018) también productor de ausencias, como atestigua una rápida consulta en las numerosas actas de congresos de la IASPM, de este y del otro lado del océano -o de la línea abismal (SANTOS, 2014). Debemos observar además que muchos estudios de música popular se basan también en la personalidad artística y toman como unidad de análisis privilegiada la obra de los músicos populares (sean canciones, discos, conciertos, etc.). Cuando este análisis es sobre el lenguaje musical, en buena medida lo que se analiza es el tipo de procedimientos en torno a la armonía, que en muchos casos generan incluso clasificaciones por estilo. De modo que la mayoría de las nociones nucleares del paradigma de la musicología son transferidas al estudio de la música popular al considerarlas parte de la naturaleza misma de la música. Las que sin embargo, como ya advertimos, no tienen

\footnotetext{
sidades comerciales de la industria musical (SCOTT, 2014). Por último, su historia de la música popular del siglo XIX en E.E.U.U. y Europa occidental es, sino la única, la mejor sobre el tema (SCOTT, 2011)

9 Solo para dejar claro de lo que estamos hablando, mencionemos que la principal institución que nuclea estas investigaciones es la descentralizada IASPM, Organización Internacional para el Estudio de la Música Popular, que como sabemos tiene su rama latinoamericana. Y una de las publicaciones más prestigiosas -y pionera- es la ya citada Popular Music de la Universidad de Cambridge.
} 
nada de natural y son las principales responsables de la producción activa de la ausencia de historicidad de la música popular.

\section{La historiografía musical y las formas de deshacerse del pueblo}

Queremos llamar aquí historiografía de la música a la producción en la cual confluyen diferentes tradiciones disciplinares vinculadas a la investigación musical. Si consideramos a la historia de la música como recuerdo científicamente formulado (DAHLHAUS, 1997), elaboración y relato (CARR, 2006; WHITE, 2010; VEYNE, 1984; CHARTIER, 2007), más allá de las denominaciones o el corpus de cada disciplina particular, toda investigación que persigue como objetivo historizar el devenir musical participa de la historiografía de la música. Fundamentalmente por esta última razón -la vocación cuanto menos declarativa de desplegar una perspectiva histórica- reconoceremos como constitutivas de la historiografía musical a tres disciplinas: la musicología histórica (que en muchas ocasiones se denomina musicología a secas ${ }^{10}$ ), pionera de los estudios sobre música a partir de fines del siglo XVIII; el folklore, surgido en la misma época y sucedido parcialmente por la musicología comparada; y -aunque tangencialmente y a contrarrelieve- los popular music studies (PMS), que configuran un conjunto de estudios recientes y algo diversos epistemológicamente.

Existen, claro está, otras disciplinas dentro del estudio científico de la música que no incluimos dentro de la historiografía musical, precisamente porque priorizan enfoques que fundamentalmente no son históricos: la teoría musical (o musicología sistemática) que no se interesa por lo que los compositores hicieron en el pasado (BECKLES WILLSON, 2009, p. 39). También el enorme campo de la etnomusicología, que justamente para evitar el enfoque etnocéntrico y primitivista ${ }^{11}$ del folklore hacia las músicas de lo que entiende como otras culturas, se abstiene en general de historizar ${ }^{12}$, aplicando una perspectiva ante todo sincrónica y antropológica (STOBART, 2009, p. 104). O la sociología musical, que por caso estudia las mismas categorías de "música culta" y "música popular" (ELLIS, 2009, p. 47), por lo que influirá muchísimo en los PMS y producirá en parte el enfoque presentista, pero también explica una parcialidad que no reconocemos dentro de la historiografía musical. Por lo cual la inclusión, junto a la musicología y el folklore, de los PMS en la historiografía musical es ambigua y parcial, y corresponde sobre todo a la producción activa de un tiempo histórico inexistente. Mientras sus postu-

\footnotetext{
10 Lo cual llevó a los etnomusicólogos, como Charles Seeger, a quejarse de que los historiadores "han secuestrado el término musicología" (citado en PELINSKI, 2000, p. 21). Este comentario prácticamente nos exime de explicar los motivos por los cuáles no incorporamos a la etnomusicología como parte de la historiografía musical, ya que no pareciera reconocerse entre los "historiadores".

11 Las historias de la música del siglo XIX y principios del XX solían comenzar con un examen de la música egipcia, griega, china o hindú para luego pasar a lo "verdaderamente importante" (COOK, 2001). Casos notables son los volúmenes de Parry (1896) y Selden Pratt (1905), que corroboran esa pertenencia dual de musicólogos y folkloristas.

12 En el esquema que estamos sugiriendo desde luego pueden pensarse numerosas excepciones. Por ejemplo, es significativo el volumen colectivo Ethnomusicology and Modern Music History (BLUM et. al., 1993) en el cual escriben etnomusicólogos muy prominentes, como Anthony Seeger, Regula Burckhardt, Thomas Turino o Phillip Bohlman. Sin embargo, en términos generales, la identidad de la disciplina no la representan los planteos históricos, y creemos que un indicador de esto es el fracaso de la tantas veces añorada convergencia entre musicología y etnomusicología, que no ha hecho más que fracasar reiteradamente.
} 
lados, teorías y metodologías han aportado enormemente a la presencia y valorización académica de la música popular (CANO Y SANS, 2011) su límite temporal -tecnológico y moderno- produce la inexistencia de una historia de la musica popular anterior al fonógrafo. Esto hace que las historias que sí se han escrito de la música popular, aunque generalmente no aparecen con un formato integrador ni bajo ese título, hagan comenzar a esta tipología musical, como muy temprano, en torno al 1900, y en general, hacia 1950. Lo cual produce activamente la ausencia de una historicidad para la música popular, sin que sea necesario siquiera enunciarla. Si revisamos qué historias de la música popular se han escrito, incluso desde el sur global, podremos comprobarlo rápidamente. Por ejemplo, en la muy premiada Historia social de la música popular en Chile, Juan Pablo González, Claudio Rolle y, luego, Oscar Ohlsen, dejan en claro, ya en el título de sus dos volúmenes, esta marca temporal: 1890-1950 para el primero, 1950-1970 para el segundo (GONZÁLEZ \& ROLLE, 2005; GONZÁLEZ et al., 2009). De igual modo, la que tal vez sea la más bella historia sobre las músicas del caribe, la Breve historia social de las bailables músicas mulatas de Ángel Quintero Rivera (2009), texto fundamental cuyos aportaciones en términos de análisis y de relación entre la materialidad sonora y la configuración social de las músicas son incalculables, también se autolimita y "concentra en procesos del último siglo" (QUINTERO RIVERA, 2009, p. 70), es decir, del XX. Mucha información puede extraerse de estos trabajos, o de otros, aún cuando esto debe realizarse sorteando los obstáculos que una larga tradición folklorizante todavía erige. Por ejemplo en otro autor fundamental de nuestra región, Antonio García de León Griego, cuyo El mar de los deseos (2002) traza definiciones importantísimas que tienen derivaciones historiográficas potenciales, que sin embargo no aparecen en el texto. Más aún, su Fandango, el ritual del mundo jarocho a través de los siglos (GRIEGO, 2006) comienza con un epígrafe de Carlos Vega que concentra lo más recalcitrante del pensamiento folklórico, en tanto concibe a lo popular como supervivencia vigente de un arte "superior" extinto. Sesgo que permea todo el texto de Griego, que sin embargo es un gran aporte de análisis socio-cultural sobre el fenómeno del fandango. Y podríamos añadir a la lista autores cubanos imprescindibles, como Alejo Carpentier, Argeliers León o Leonardo Acosta, todos los cuales, en su dimensión historiográfica, reproducen la división tripartita del campo musical que escinde lo popular de lo folkórico, recayendo la historicidad exclusivamente en esta última categoría.

Casos más recientes incluyen perspectivas muy interesantes, pero que al estar circunscritas a géneros musicales o geografías muy restringidas, impiden ponerlas en relación con una narrativa amplia que contraste con los alcances aun vigentes de la historiografía afirmativa. Un trabajo pionero a nuestro juicio es el de Carolina Santamaría sobre el Bambuco (SANTAMARÍA, 2007) ${ }^{13}$ en el que introduce una muy interesante concepción de lo mestizo en torno a la historia de ese género musical, aspecto que retomaremos más adelante. También es crucial el trabajo de Ana María Ochoa, especial-

\footnotetext{
13 Como última apostilla sobre el tema, consideremos que todavía en 2020 numerosos cursos internacionales de posgrado sobre música, y en particular de Latinoamérica, proponen la categoría de lo folklórico o "tradicional" en contraste con lo "popular" o comercial. Por ejemplo en la oferta académica del muy prestigioso Consejo Latinoamericano de Ciencias Sociales, Clacso.
} 
mente el referido a la cultura de la escucha en Colombia durante el siglo XIX (OCHOA, 2014). Ambos textos, sin embargo, no sólo presentan un límite geográfico o genérico, sino que además, como en los trabajos del ya citado Derek Scott (ver nota 6) se limitan al siglo XIX como momento más antiguo. Estos umbrales deben ser trascendidos si queremos construir narrativas históricas globales, amplias, relacionales, que desplacen la hegemonía de la historiografía afirmativa y aporten a una historia popular de la música.

Puesto que trabajos recientes que articulan la musicología histórica y los estudios sobre música popular dan cuenta de la vigencia de la historiografía afirmativa, elaborando argumentaciones que remedan al positivismo, erigido ahora como fundamentación del "presentismo", que se convierte en límite infranqueable para el estudio de las músicas populares, ya no por inexistencia de la partitura, sino bajo el régimen de lo aural o sónico. Así lo que en términos de "giro sonoro" ha sido un campo de estudios muy fértil, reclamando fatigosamente incorporar la materialidad del sonido a una musicología que siempre se dedicó a encubrirlo -aún cuando también se orientó mayoritariamente al siglo XX, al punto de llamarlo "el siglo del sonido" (OCHOA, 2011)- es transformado en una falsa excusa para decretar la inaudibilidad de toda música popular anterior a las tecnologías y la industria de la grabación, ya que quienes pretenden historizarlas "si bien tratan de prácticas musicales, no pueden ocuparse del sonido per se -al menos no como elemento central- por razones metodológicas" (BIELETTO, 2016). Comparando estas argumentaciones con el epígrafe de Grout del comienzo, podremos constatar hasta qué punto están vigentes los sesgos de la historiografía afirmativa. Puesto que reintroducen un diferencial metodológico entre música culta y popular en base a la posibilidad de recuperación de su sonoridad pretérita. Precisamente la posibilidad de historicidad de la música popular reside en rechazar ese diferencial, reconociendo de una vez que todo sonido pasado se ha perdido, los escritos y los que no, los cual nos exige construir nuevos útiles de investigación. Debemos despertar del sueño del positivismo y el historicismo musical, invertir y carnavalizar la historiografía musical ${ }^{14}$.

El límite temporal de los estudios de música popular es entonces, a todas luces, autoimpuesto, y por ello no sorprende que lo encontremos en las mismas definiciones de sus principales practicantes:

[música popular] trata de una práctica musical urbana o urbanizada, que es definida por su masividad, mediatización y modernidad. De este modo, quisimos diferenciarnos de las prácticas musicales tradicionales, comunitarias y orales [...] una música mediatizada, masiva y modernizante (González, 2008, p. 4)

Si bien hay muchas diferencias entre las inscripciones teóricas e ideológicas de los PMS, frente a la connivencia de la musicología histórica y el folklore, los tres componen-

\footnotetext{
14 El interesantísimo dossier sobre "Música, historia e historiografía" de la revista Resonancias, del que forma parte el encendido ensayo de Bieletto, desliza también, en la introducción del editor, que "una de las operaciones historiográficas fundamentales en torno a la investigación musicológica del período colonial americano [es] la periodización y su consiguiente discusión estilística" (RONDóN, 2016, p. 10). Alli no hay ninguna duda de que cuando se trata de compositores de música oficial o culta, podemos analizar su sonoridad como si viajáramos en el tiempo. Los mismos elementos que aquí estamos identificando como estructura del carácter afirmativo de la historiografía musical, continúan siendo celebrados en nuestro tiempo, incluso por textos críticos o revisionistas.
} 
tes de la historiografía musical participan de una escisión moderna y occidentalocéntrica del campo musical, abordando objetos de estudio que se presentan esencialmente diferentes, de tal suerte que una hipotética articulación entre ellos nos devolvería un panorama altamente fragmentado (KERMAN, 1985): los estilos compositivos clásicos, los otros racializados-territorializados, y los objetos industriales del mercado contemporáneo.

Como resultado historiográfico general, y en tanto producción activa de ausencias, cuando se ubican estos vectores en yuxtaposición, surge un panorama global, si bien fragmentado, que consideramos responsable de muchas falacias históricas importantes, que habitan sobre todo en los imaginarios sociales y en el sentido común de la mayoría de nuestros pueblos. Así:

- la única tradición musical histórica es la que pertenece a la música culta, periodizada en estilos y que comienza en la Edad Media ${ }^{15}$, historia que ya terminó su devenir a principios del siglo XX;

- el arte popular temporalmente remoto es folklore, no historia, y por lo tanto es estático, rural, ingenuo y reaccionario; como también ya terminó, sólo es posible su preservación patrimonial;

- la música popular no tiene historia y tampoco tradición. Recién comenzó. Por eso ocupa los capítulos del siglo XX-XXI en los manuales de historia de la música, y nunca aparece en capítulos anteriores.

Más que en la producción escritural estrictamente científica, en dónde desde hace décadas se rehúye la elaboración de narrativas históricas de largo aliento en sintonía con el giro epistémico de las ciencias sociales en general y el impacto de la New musicology en particular, es en los libros de texto para el grado universitario o de divulgación y por ende en los programas de tv, las charlas abiertas y los cursos de historia de la música (también en la universidad) donde podemos encontrar de forma explícita estos sesgos $^{16}$. Son varios los números del Journal of Music History Pedagogy en los que diversos autores vienen señalando esta circularidad y connivencia entre los sesgos disciplinares y los esquemas narrativos sobre la historia de la música. Sin ir más lejos, el primer artículo de la edición 2020, comienza argumentando la vigencia de esa articulación, mediante

\footnotetext{
15 No sólo hacemos comenzar la historia literalmente en el medio, sino que además reproducimos una periodización que según Enrique Dussel es una "estúpida ideología del romanticismo alemán" (DUSSEL, 2007)

16 No es este el lugar en donde analizar las transformaciones en la musicología a partir del advenimiento del paradigma "crítico", irradiado no únicamente pero especialmente desde las academias anglonorteamericanas. Pero baste decir que su producción se circunscribe en su enorme mayoría a los estudios de caso, y por lo tanto su impacto en una historia de la música es muy relativo, a pesar de que se han puesto en crisis las categorías centrales de la musicología afirmativa, como la noción de obra y se han desarrollado auspiciosamente los estudios de la performance, entre otros muchos aportes. Aún así nuestra visión histórica de conjunto no se ha modificado significativamente, puesto que los taceles de la musicología crítica no forman, ni siquiera, un mosaico. Son preciosos fragmentos unitarios, muchos de ellos de gran profundidad y erudición, que sin embargo no se hilvanan entre sí. Esta tarea está aún pendiente. Y se aprecia cuando sus mismos representantes se ven requeridos a escribir una historia de la música, aunque sea como libro de texto escolar. Un caso muy flagrante que hemos analizado en otro trabajo (Eckmeyer, 2014) es el de Listen, de Joseph Kerman y Gary Tomlinson (2012), dos pilares de la new musicology, que sin embargo en este libro reproducen todos los sesgos de la musicología afirmativa. En nuestro medio puede pensarse en la "historia de la música" de Pola Suarez Urtubey (2007) o la pintoresca O som e o sentido. Uma otra historia das músicas de José Miguel Soares Wisnik (2015), que a pesar de lo que promete en su título, reproduce un vector que va de la "antropología del ruido" de los primitivos africanos, pasando por lo modal del mundo musulmán, para terminar, vía la tonalidad europea, en la síntesis de las "simultaneidades" que presenta la música contemporánea "del norte", todo articulado en base a los grandes nombres de Mozart, Wagner, Webern o Cage. Es decir, su índice no difiere significativamente del texto del estadounidense Waldo Selden Pratt publicado en 1905, que separaba de forma evolutiva las músicas de los primitivos, de los pueblos semi-civilizados y, finalmente, de la civilización occidental. Esta es la vigencia del modelo historiográfico afirmativo de la que estamos hablando.
} 
la cual la estructura de la musicología histórica positivista de mediados del siglo XX permanece intacta en la currícula de los programas de grado de las universidades de EEUU y Canadá, a pesar del (aparentemente) fuerte giro disciplinar (WALKER, 2020, p. 1). En un breve recorrido por sus contenidos podremos formarnos algunas nociones sobre la música, como por ejemplo que "las culturas no occidentales encarnan los comienzos y la cultura occidental el progreso" (COOK, 2001). Pero además que la música culta de concierto está esencialmente "muerta", lo que equivale a decir que es histórica, y por lo tanto canónica, clásica y venerable. En su borroso apéndice, su continuidad a partir de 1909, se eterniza como "contemporánea", experimental, representando el futuro, aunque hayamos rebasado ya su centenario. Entonces (¿para no ahuyentar a los lectores?), el foco de interés se traslada a la música de la cultura de masas, en especial la de la industria cultural anglo-norteamericana de la segunda mitad del siglo XX. En resumen: las músicas no occidentales son pre-historia, aunque se conciben inmutables a partir del núcleo difusionista y evolucionista del folklore; la "Música" es culta, escrita en partitura, del occidente europeo, con una larga, esotérica e ineludible historia que comienza con la escritura, aunque es míticamente heredera de la Grecia Clásica o hasta de Dios ${ }^{17}$; y finalmente la música popular inicia su breve historia en los comienzos del siglo XX, convirtiéndose en la música masiva y comercial de la actualidad.

Esta serie de nociones que se reproducen de forma bastante acrítica u oculta son causa y a la vez efecto de este esquema de la historiografía musical, porque parten de la circularidad entre la faceta escritural y la disciplinar de la historiografía musical; configuran una suerte de verdades historiográficas muy resistentes al cambio: la separación compositor/actuante; la identificación del hecho musical con un objeto/obra que se explica como forma; la periodización en estilos; la confusión entre soporte, fuente y hecho musical; y la atribución histórica de la música sólo en base a su fecha de composición, única inscripción posible de creación.

Si bien todas ellas han sido formuladas para blindar la exclusividad histórica de la música de la monocultura de la modernidad burguesa, la mayoría de los PMS, cuando historizan, no se permiten periodizar de otro modo, pensar en base a otros indicios y fuentes, y/o apartarse de la figura del creador/compositor. A lo que debemos añadir un útlimo rasgo en los PMS, junto a la perspectiva presentizada y la continuidad de las nociones mencionadas arriba. Es el cuestionamiento persistente a la pertinencia de establecer relaciones entre la música y la estratificación social. En las mismas definiciones de su objeto de estudio, los investigadores de los PMS rehusan explícitamente establecer vinculaciones directas entre "lo popular" y alguna categoría del "pueblo", lo "subalterno" o el mundo de los oprimidos, entre algunas otras posibilidades. Y esto a

\footnotetext{
17 Nuestra intención no es hacer aquí una humorada. La historia de la música tradicional reprodujo durante muchísimos años la noción de que el primer repertorio de la música occidental, el canto gregoriano, fue producto del Papa Gregorio I (Magno). Esta concepción se basaba en una adjudicación medieval de fuerte raigambre religiosa, que sostiene la revelación del canto cristiano al Papa a través del Espíritu Santo, quién lo dicta al oído del pontífice transformado en una paloma posada sobre su hombro. Coincidentemente con todos los postulados de la estética medieval -que constituyen la base de la estética musical occidental- el canto era demasiado perfecto para ser obra del hombre (música humana): necesariamente debía ser obra de Dios (música mundana). Tal el mito fundante de la tradición clásica europea occidental, presente hasta el día de hoy en los textos de historia de la música. Abordajes críticos de este tema pueden encontrarse sobretodo en Treitler (1991), y también en Griffiths (2009) o Taruskin (2005).
} 
despecho de que muchas veces se problematice en congresos y publicaciones la relación "música popular y política". Aunque en realidad deberíamos observar que aquí opera el mismo mecanismo que la musicología afirmativa, autonomista, desplegó para tratar las excepciones "politizadas" de la música culta (CANNOVA, 2008), que terminan convirtiéndose en anomalías. De igual modo que decir "música y performance" no hace más que profundizar la escisión entre ambos términos (Cook, 2011), el enunciado anterior pone fuera de la música popular a su dimensión política, que por lo tanto puede o no invocarse a la hora de historizar estas manifestaciones. Sin ir más lejos, el quinto elemento de la definición más famosa de popular music, que coincide significativamente con la ofrecida por Juan Pablo González citada unas páginas atrás, lo deja muy claro: "Música que es formalmente híbrida, que reúne elementos musicales que atraviesan los límites sociales, culturales y geográficos" (FRITH, 2004, p. 4).

Desde ya es muy positivo que no haya en los PMS un mecanicismo sociológico vinculando formas musicales con clases sociales. Pero el relativismo social ha llegado a tal punto que desembocó en una nueva clase de autonomía musical, lo cual hace resonar una vez más las formulaciones autonómicas de la musicología histórica (el genio por fuera de la sociedad) y del folklore (el pueblo por fuera de la sociedad y la historia). Si bien casi todos los trabajos importantes de los PMS problematizan explícitamente lo "popular", en línea con la tradición de los estudios culturales, es cierto también que aducen no poder establecer relaciones entre los musical y lo social o político. Pareciera que intentan sacarse el problema de lo popular de encima, como puede leerse directamente en el número 2 de la revista Popular Music, donde se reproduce un debate a modo de foro entre varios de los más ilustres fundadores de la tendencia, que lleva un significativo título que es posible traducir así: “¿Podemos deshacernos del "pueblo" en música popular?"18 (THE INTERNATIONAL ADVISORY EDITORS, 2005). A lo cual deberíamos añadir el derrotero del término y su contrastación activa, en nuestra región, frente a lo que folkloristas y musicólogos históricos (Andrade, Vega, Ayestarán) llamaban música popular, que vendría a ser algo diferente a popular music (GONZÁLEZ \& SMITH, 2012). Esta discusión no ha quedado saldada ni ha producido el abandono o modificación del término, pero nos indica la presencia de una perspectiva muy difundida en los PMS.

Son entonces los mismos textos y argumentos de los musicólogos, los folkloristas y -hasta cierto punto- los PMS, quienes resumen posiciones frente al "pueblo" que resultan en cierto grado de convergencia y configuran una especie de dominocentrismo (GRIGNON Y PASSERON, 1997). De las expresiones que venimos refiriendo se deducen lo que podríamos llamar tres sentencias musicológicas mediante las cuales las músicas históricas del mundo popular subalterno son arrojadas fuera de la historia: 1) Para la musicología histórica, epitomada por Grout, la Música no es popular. 2) Para el folklore, definido por Herder, el pueblo no es el pueblo. 3) Para el sector dominante de los PMS, representados por Frith o González, la música popular -todo en minúscula- debería no ser popular. 


\section{La historiografía musical y la afirmación de lo existente}

Entonces, como característica de la historiografía musical ampliada, encontramos lo que denominaremos su carácter afirmativo, responsable de que no emerja dentro de la historia musical la banda sonora de las clases subalternas, sea de los nómadas o artesanos medievales, mineros y marineros de la modernidad temprana, dependientes racializados indígenas, mestizos o pardos, esclavos afroamericanos, o jornaleros y trabajadores de los inicios de la sociedad industrial; que pensemos que o vivían en silencio, o cantaban las mismas canciones bucólicas que sus inexistentes parientes "del campo", o consumían con fruición la misma música de las élites. Parece absurdo, pero creemos en un pasado intrínsecamente silencioso del mundo popular subalterno, antes de la aparición de la radio o el fonógrafo. Y de pronto estas ruidosas muchedumbres irrumpen en escena, con sus cuerpos en el centro de las ciudades, sus reclamos políticos, sus formas de organización y, claro está, con sus músicas. Como no sabemos de dónde salieron -no podemos saberlo mediante esta historiografía- remedamos sin querer la sorpresa neomalthusiana de los sectores acomodados cuando veían desfilar por "sus" calles y plazas a los sectores subalternos. Algo que antes de la sociedad industrial era un paisaje -sonorofrecuente, espacio urbano de tensiones y disputas que solo la configuración de la ciudad burguesa industrial del siglo XIX segregará en barrios definitivamente apartados.

Estos problemas e interrrogantes no pueden ser saldados mediante el recurso a una inaudibilidad producto de un hipotético silenciamiento que el poder haya producido en el pasado hacia los sectores populares, en el sentido de lo que se ha olvidado socialmente, como pretenden ciertos enfoques actuales articulando perspectivas de la musicología y la etnomusicología (BIELETTO, 2016). El mundo popular subalterno siempre fue ruidoso y desbordante, sufriendo sin dudas las respuestas cohercitivas del poder, pero que más que silenciarlo ha procedido a regularlo e intervenirlo (BURKE, 2014), intentando domesticarlo. Amílcar Cabral (2013) ya explicó brillantemente que la dominación o elige el genocidio del otro, o intenta armonizar sus estructuras económicas y políticas con las costumbres culturales de los oprimidos. La producción de ausencias que estamos refiriendo, como consecuencia del carácter afirmativo de la historiografía musical, pretende precisamente eso: encontrar una enunciación de la música popular que al mismo tiempo que neutraliza sus ruidos y encubre su historicidad, produce un enunciado en presente que la hace compatible -e incluso funcional- con la construcción de hegemonía.

Parafraseando a Terry Eagleton (2006) podríamos decir que si para la burguesía moderna es tan importante hablar de música -en términos de estilos, obras y autores, de saber sus biografías o el detalle de armonías y orquestaciones- es porque, sencillamente, al hablar de música se está hablando también de otra cosa.

A las demandas acusadoras la burguesía dio una respuesta decisiva: la cultura afirmativa [...] A la penuria del individuo aislado responde con la humanidad universal, a la miseria corporal, con la belleza del alma, a la servidumbre externa, con la libertad interna, al egoísmo brutal, con el reino de la virtud del deber. Si en la época de la lucha ascendente de la nueva sociedad, todas estas ideas habían 
tenido un carácter progresista destinado a superar la organización actual de la existencia, al estabilizarse el dominio de la burguesía, se colocan, con creciente intensidad, al servicio de la represión de las masas insatisfechas y de la mera justificación de la propia superioridad (MARCUSE, 1967, p.52)

Podemos pensar que la historiografía musical, así planteada, está elaborada para hacernos creer en un orden consensual del mundo (ATTALI, 2011) e integrarnos en una falsa comunidad cultural, a la vez local y universal. Mediante la afirmación de la belleza clásica, todas y todos participamos de una felicidad abstracta, espiritual, que contradice las penurias de la sociedad material. En esta historia musical, que parece la única posible, se nos hace sentir felices aunque no lo seamos en absoluto. De ahí que la predilección por la autonomía artística no sea un capricho esteticista, sino una necesidad por obscurecer las relaciones materiales de la música y producir el hechizo afirmativo.

Como contracara del arte que así pasa a ser "culto", la cultura afirmativa, en el mismo momento histórico y social, configura un mundo idealizado y romántico en el cual los sectores populares pueden tener una existencia evasiva, idealizada y fundamentalmente a-histórica.

[El] Folklore capta ante todo un movimiento de separación y coexistencia entre dos "mundos" culturales: el rural, configurado por la oralidad, las creencias y el arte ingenuo, y el urbano, configurado por la escritura, la secularización y el arte refinado; es decir, nombra la dimensión del tiempo en la cultura, la relación en el orden de las prácticas entre tradición y modernidad, su oposición y a veces su mezcla (MARTíN-BARBERO, 1991, p. 19).

Lo primitivo, lo irracional, lo bucólico e incluso lo exótico que se atribuye al pueblo folklorizado también logra así constituir un mundo apartado, desarticulado del mundo de las relaciones materiales. Los moradores del folklore no tienen nada que ver con el mundo de todos los días de la sociedad burguesa, que explota de contradicciones y rebosa de conflictos.

El folklore, como disciplina y configurador de sentidos sobre el pueblo y su música, participa de la cultura afirmativa y su construcción mediante sus propios útiles de conocimiento: el objeto etnologizado de cancioneros, folksongs y danzas, o el sujeto colectivo del volkgeist, junto a una particular clase de autonomía derivada de la territorialización y el abuso de la dicotomía -extremadamente burguesa- de lo urbano contra lo rural. Estos elementos convergerán en un modelo de epistemología musical racializado que será el homólogo del paradigma de los estilos de la musicología histórica. Entonces, el modelo objetual/personalista también informa al folklore, incluso con mayor grado de sofisticación.

En las disciplinas que incluimos en nuestra definición de historiografía musical hay una convergencia no sólo epistemológica y estética, sino -al menos parcialmente-ideológica y económica (los PMS participan, como aclaramos antes, solo tangencialmente en el carácter afirmativo, especialmente al no contestar esta producción activa de ausencias). Esa ideología, que produce la inexistencia histórica de la música popular al tiempo que la introduce en el mercado como valor de cambio, reservándole un lugar en 
la cultura entre lo primitivo y lo momentáneo, la designamos como modernidad (DUSSEL, 2007), en términos de proyecto civilizatorio, nutrida de todos sus sesgos específicos: racial, colonial, de clase, de género, entre otras relaciones de opresión (GROSFOGUEL, 2014). Sesgos que en simultáneo oculta y encubre de la producción musical, que sí suscribe como historia de la música.

Para describir esta convergencia podemos tomar como base la conceptualización que Florencia Garramuño utilizó para establecer la relación, al mismo tiempo académica y mercantil, en torno a las músicas populares y vanguardistas de Sudamérica al insertarse en el mercado transnacional de principios del siglo $X X$ : a este proceso de rechazo y fascinación -actitudes que encontramos tanto en el folklore como en la musicología- lo llamó "modernidad primitiva" (GARRAMUÑO, 2007). Es muy interesante descubrir que Julius Reder Carlson (2013) elige aplicar este concepto a la emergencia de Andrés Chazarreta y su compañía de música nativa (patriarca del folklore argentino), desplazando lo que Garramuño encuentra en repertorios de la musicología histórica (la vanguardia) o de los PMS (el tango), hacia la problematización del folklore, su condición de música comercial y fonográfica, y la apelación al pasado de la tradición.

Este aporte dual de Garramuño/Carlson, que explicita las contradicciones inherentes a la historiografía afirmativa al promocionar estética y comercialmente lo que al mismo tiempo se rechaza u oculta, puede extenderse a las actitudes de las restantes disciplinas, puntualizando en cada caso el vector o dimensión que funciona en cada campo como concepto base. De este modo encontramos que la musicología se funda en una genealogía cuasi aristocrática que deriva el prestigio de la extensión histórica hacia el pasado, resultando en una modernidad histórica; por su parte la apelación a la comunalidad, lo iletrado y el primitivismo formulan la modernidad primitiva del folklore; mientras que el acento en convertir a las tecnologías de la grabación y difusión radiofónica en sinónimo de "tecnología" y "mediatización", desconociendo la matriz tecnológica de otros medios musicales del pasado histórico y su rol en la circulación musical, hacen de los PMS una modernidad tecnológica ${ }^{19}$. Tres dimensiones de la ideología musical de la modernidad que se corresponden con lo que antes llamamos las tres sentencias musicológicas.

De esta suerte de arreglo de dimensiones específicas (lo histórico, lo primitivo y lo tecnológico) surgen los sesgos de cada disciplina, ya que la hiperbolización de cada dimensión produce la atrofia de las otras: si el folklore es antes que nada primitivo, entonces no puede ser histórico y sus medios rudimentarios no serán considerados tecnología; si la música culta adquiere su valor estético en función de su longeva historia, entonces ya no será primitiva, porque es "superior", pero su historicidad y clasicismo no podrán confundirse con los medios técnicos, urdidos con fines mercantiles y no estéticos. Si la popular music es antes que nada un subproducto de la fonografía y el merca-

Nuevamente, expresamos el reconocimiento hacia los practicantes de los PMS que han presentado posturas críticas frente a la modernidad. Pero a nuestro favor queremos señalar que, en su versión más habitual, lo han hecho desde lo que podría englobarse como posiciones posmodernas. Al respecto los autores identificados con el colectivo "modernidad/colonialidad" han propuesto la consideración de lo posmoderno como parte de la modernidad, incluso como un segmento crítico pero interior: «posmodernidad que es todavía un momento final de la modernidad» (DUSSEL, 2005, p. 16). Recogemos esta interpretación de lo posmoderno para ubicar a los PMS en todo caso en relación directa, incluso crítica, con la modernidad. De hecho su acento en los medios tecnológicos pueden considerarse un culto a uno de los hitos fundantes de lo moderno en el siglo XX. 
do, su alcance será el presente, y por lo tanto no será ni histórico ni primitivo, pues sus medios son demasiado modernos para confundirse con los hontanares de la música.

Si consideramos el momento de eclosión de estas modernidades, veremos que los hitos de sus repertorios siempre se estudian por separado, limitando el análisis a la vez que se abstraen las músicas de sus ocasiones de referencia, vínculo que contiene precisamente una potencia histórica y explicativa de mucho valor. Por ejemplo solemos pensar en la música de las vanguardias históricas únicamente mediante las categorías que hacen a su lenguaje interno, es decir desde una modernidad histórica. ¿Qué consecuencias historiográficas tendría considerar el auge de los medios fonográficos y la crítica musical de la prensa en relación con la circulación de la segunda escuela vienesa? ¿Qué otras escuchas de las músicas de Debussy, Stravinsky, Williams o Ginastera nos habilitaría el estudio profundo de las ideologías del folklore? ¿Cambia el jazz si lo hacemos retroceder hacia el minstrel show, o incluso al café concert, ambos asuntos erigidos como contracara del folklore, donde a su vez se confinó racializado al blues, que finalmente informa al jazz? ¿Por qué las historias de la música culta de principios del siglo XX no incluyen las modificaciones que la grabación les introdujo en sus prácticas compositivas, interpretativas y de producción musical, así como los cambios en los roles y criterios de orquestación? ¿Era el empujador de la grabación analógica un músico que debe estar en la historia? ¿Puede estudiarse de forma sincrónica el rock y la música electroacústica, ambos emergentes de tecnologías comunes pero también de vectores históricos de larga duración diferenciados? No interesan aquí las posibles respuestas, sino la posibilidad de interpelar al pasado con otras preguntas que permitan establecer relaciones indisciplinares ${ }^{20}$ entre las simultaneidades de lo que hoy son asuntos de mundos distintos, disciplinados por la fragmentación de la historiografía musical afirmativa.

Nos cuesta hacerle esas otras preguntas al pasado sonoro (Small, 1999). Sobre todo en su arista musicológica, la historiografía afirmativa persiste con una resistencia insospechada, cuando no puede ya explicar casi nada de las prácticas y las relaciones de las músicas tal cual las conocemos o practicamos hoy. Incluyendo los artefactos de la concepción presentista de los PMS dominantes. Y así como el neoliberalismo no puede explicar las extremas inequidades del siglo $\mathrm{XXI}^{21}$ en un mundo en que el déficit alimentario se ha resuelto en la teoría pero no en la práctica, el vacío explicativo de la musicología histórica y el folklore no puede explicar la música de un mundo transcultural, que lucha por la equidad de género y la ampliación de derechos, que promueve el respeto por las disidencias sexuales, en el cual las explicaciones proceden de nuevas narrativas

\footnotetext{
20 Estamos haciendo referencia a in-disciplinar lo que ya forma parte de las epistemologías musicales, más allá de que deban ser profundamente reformuladas e invertidas. En cambio, los muy mentados "estudios interdisciplinarios" sobre música, que han producido enormes aportes y han abierto muchísimo el campo de estudios musicales, han generado sin embargo problemas en torno a la especificidad de la epistemología musical, además de serias discusiones en torno a la procedencia (otra vez disciplinar) de los investigadores. Como efecto no deseado de esta ampliación, han aparecido recientemente algunos reclamos que vuelven a instalar la autonomía musical como límite de lo que es (y no es) lo musical, o malentendidos en torno a lo que significa que en los estudios sobre música haya, precisamente, música. Esto se aprecia muy notablemente en un manifiesto de un grupo de investigadores que provienen de los PMS (el NIMiMs) que es contestado por la mencionada musicóloga Natalia Bieletto (2016). Tanto el "presentismo" de los primeros, como la persistencia de la confusión entre "materialidad musical" y "análisis estructural" en la segunda, no hacen más que ejemplificar nítidamente lo que aquí analizamos como rasgos específicos de la historiografía musical afirmativa.

21 Y por esta misma razón fue calificado como zombie por Álvaro García Linera (2018) y también por Paul Krugman (2019)
} 
"desde abajo", el "out of África", las teorías de la subalternidad, las epistemologías del Sur o las perspectivas decoloniales. Vacío que roba la dimensión sonora de la historia de todos estos procesos y luchas. Ausencia que no pudo ser saldada por los PMS.

La historiografía musical afirmativa es entonces una historiografía zombie, que se arrastra gruñendo y dando tumbos por los pasillos de las instituciones de formación musical.

Por esta estrecha relación entre la estética burguesa, la historiografía afirmativa y la política, no debemos malinterpretar el término: lo afirmativo/zombie, como parte de la cultura de la modernidad/colonialidad no es para nada débil. Ahora mismo estamos presenciando como en el mundo los odios y resentimientos emanados de ideas que ya no explican nada juegan con la vida de millones en el marco de la pandemia por el covid-19. Parece menor y superfluo, pero mentir en musicología, contribuyendo a la cultura afirmativa mediante la negación de las condiciones materiales y la dimensión histórica de las prácticas musicales del mundo popular subalterno, es decir, mediante la producción activa de su ausencia, también atenta contra la vida y es antidemocrático. Porque se expulsan los sentidos sonoros de las mayorías de la narrativa histórica y se naturalizan, desde una faceta sonora, las inequidades históricas. Aquí se advierte el contagio zombie hacia los PMS: retomando el análisis de Bruce Johnson vemos que el modelo presentista impone serias limitaciones a toda perspectiva histórica -entre otras cosas la de los cambios históricos del mismo concepto de lo "popular"- al tiempo que hace inexistente, también en el presente, lo que es "el mayor conjunto de producción musical [...] un hacer musical que es voluntario pero no se registra en ningún formato audiovisual para su distribución comercial [...] Subrayo hacer musical."22 (JOHNSON, 2018, p. 16)

Precisamente, si dejamos de lado por un momento el paradigma objetual de la historiografía afirmativa, la música puede ser comprendida ante todo como práctica social, a condición de que en lugar de reconocerla como objeto nos enfoquemos en su aspecto práxico, lo cual debería incluso ser parte de nuestro sentido común sobre ella. Los llamados estudios de la performance han advertido en las últimas décadas sobre esta irreductible condición social, incluso cuando se trata de una práctica musical en solitario (COOK, 2011, p. 186), lo cual ha vuelto obsoleto insistir con la dicotomía (falsa) entre música y sociedad. Sin embargo la línea principal de esta tendencia de investigación musicológica continúa pensando a la música en tanto "texto" o, a lo más, como "guión". Es decir, conserva lo que Attali llamaba matriz, la producción del autor, lo cual tiende a reproducir la división de roles y la misma concepción de música de la modernidad. Cook establece, por ejemplo, una analogía entre el guión que habilita la performance y la labor de un coreógrafo (2011, p. 187). Además es una tendencia que se ha enfocado principalmente en el estudio del presente o, en el mejor de los casos, a establecer comparaciones entre grabaciones de performances. Por lo tanto, antes que pensar que los estudios de la performance participan del mismo "presentismo" que los PMS, sería mejor considerarlo parte de un enfoque antropológico, sincrónico, emparentado en todo 
caso con la etnomusicología. Razón por la cual su impacto historiográfico viene siendo más bien escaso.

Pero la principal limitación de los estudios de la performance para acercarnos a otra definición histórica de música popular, es que más que revelar, enmascaran el hecho de que la acción implica la transformación continua de la música. Es decir, debemos atrevernos a ir más allá, incluso, de pensar la acción sonora como "instanciaciones" de una identidad musical que reside en algún lugar previo: el guión, el texto, la matriz, o en definitiva, la obra. Aún cuando a partir de la notación o la fonografía la música habitó diversos objetos que la mediatizaron, todos entendemos que antes que cualquier otra cosa la música es un hacer: ensayar, cantar, tocar, escuchar, tararear, corear, componer, arreglar, producir, mezclar, remezclar, emitir... y una larga lista de etcéteras. La música comprendida de esta forma necesita objetos -instrumentos, amplificadores, tocadiscos, radios, computadoras, y claro está, hasta partituras- pero no es un objeto ni un texto. Y en la medida que esto sea así, constituye mucho más un proceso que una matriz, en el sentido de modificación y creación permanente.

\section{Hacia una historiografía popular de las ausencias}

Para promover una historiografía que vuelva existentes las ausencias producidas por la historiografía musical afirmativa, queremos primero proponer una ampliación cronológica de la idea de mercado musical con el objetivo de reunir prácticas musicales provenientes de diversos contextos y que poseen resultantes estéticas muy variadas, pero que comparten su carácter profesional, en base a la remuneración permanente o esporádica de sus practicantes y a la producción experta por repetición o en serie. En este sentido las ideas tradicionales del folklore acerca de la comunalidad y la ausencia de especialización no pueden ser aplicadas y revelan su obsolescencia. Por supuesto que aquí son fundamentales los aportes de los PMS, pero a condición de que no obstaculicen el desplazamiento de la barrera presentista hacia una historia mucho más amplia y antigua, examinando las relaciones de producción de estas músicas, sus públicos y formas de difusión y circulación. La muy longeva historicidad del mercado musical popular, asociado con la imprenta de baladas y canciones de por lo menos finales del siglo XVI, es ensayada por Niels Grosch (2005) e incluso Simon Frith (2006) dentro de los PMS, además del ya citado Derek Scott para el caso del siglo XIX, al que también refiere para EEUU Karl Miller (2010); aunque a nuestro entender quien sigue siendo la referencia principal es Jacques Attali (2011), particularmente en lo referido a los procesos históricos de transformación de la música en bien de cambio iniciados a finales de la Edad Media y la modernidad temprana, que incluyen también el enclaustramiento en locales específicos. Ambos son procesos históricos que comparten tanto la música culta como la popular. Esta particular concepción tiene como ventaja la supresión de algunas de las nociones historiográficas afirmativas: en particular la escisión artificial del campo y la periodización estilística armónico-autonomista, además de aportar fuentes históricas alternativas que desplazan la necesidad de la partitura como registro. 
Una vez despejado el artificio en torno a la pretensión de presentismo de lo "moderno" y "tecnológico" del mercado musical, nos encontraremos además con que la reificación y deriva en objeto de cambio de la música se opera sobre todo en la música culta, sino antes en simultáneo con la popular, en torno al dispositivo de la sala de conciertos para la ópera y sus opus. Esta constatación de la matriz culta y estratificada de la concepción objetual nos lleva a proponer una desobjetificación musical, aplicable a todo repertorio, en pos de una historiografía popular musical inclusiva: es necesario retransformar a la música en fenómeno sonoro, momentáneo, cuya re-actualización -que es actuación- involucra una re-creación dinámica permanente e histórica. Todos los aportes de los estudios sonoros o sound studies (ERLMANN, 2004) que se nutren de una larga lista de antecedentes interdisciplinarios (STERNE, 2012) -algunos de los cuáles venimos refiriendo en este texto- resultan de máxima relevancia, aunque insistiendo en dos condiciones: producir un giro historiográfico de estos enfoques; y propender a la comprensión de la cultura sonora popular en términos de acción transformadora y producción dinamogénica, y no sólo como audición.

Se nos revela entonces imprescindible, para dar cuenta de este carácter histórico y a la vez dinámico, el concepto -tan conocido como poco utilizado- de musicar desarrollado por Christopher Small (1998). Formulación particular que discute, al fin, el significado mismo de lo que entendemos por música ${ }^{23}$, que como dijimos antes no es otra cosa que el producto de los artificios metonímicos de la historiografía afirmativa. Pasar entonces de 'música' -es decir objeto- a 'musicar', es poner en el centro la acción presentacional (LANGER, 1957) en una operación más profunda de lo que aparenta. Justamente Langer construye su concepto distinguiéndolo de los enunciados proposicionales, en donde sí podríamos ubicar los "guiones" de los estudiosos de la performance, que refieren las instanciaciones a una referencia proposicional. Lo presentacional, en cambio, nos obliga a abandonar nuestros modelos analíticos, las formas de periodización y conceptualización musical de la afirmatividad. Nuestro interés ya no puede estar reducido al compositor, la partitura, el fonograma (=la obra); y las nociones de origen, estilo o autenticidad se hacen totalmente obsoletas.

\begin{abstract}
En ese mundo real donde la gente en realidad toca y canta y escucha la música, en salas de concierto y salones aburguesados y cuartos de baño y en mítines políticos, y en supermercados e iglesias, en tiendas de discos y templos, y prados y clubes nocturnos, discotecas y palacios, estadios y ascensores, es la actuación lo que es central para la experiencia de la música. No hay música aparte de la actuación, sea en vivo o grabada. [...] Entonces, me parece evidente que el punto para empezar a pensar sobre el significado de la música no son las obras musicales sino la acción (SMALL, 1999, p. 5).
\end{abstract}

Este concepto es prioritario porque expresa la idea de tomar parte en una actuación musical. Pensar la música como práctica y "ritual en el espacio social" multiplica las posibilidades de participación e incorpora una plétora de sujetos nuevos en el rela- 
to histórico. Porque además de otros espacios abre otras temporalidades, permitiendo otras historias con otras periodizaciones. Pensar la música como acción es pensar que el arte está inscrito en el cuerpo, que es a la vez un cuerpo individual y social, o incluso un cuerpo cuya subjetividad depende íntimamente de las relaciones sociales, con otros cuerpos que comparten la ocasión musical. Incluso podamos comprender así que los mayores logros expresivos se dan en la acción -no en los objetos cristalizados- pues ponen en escena el imaginario tanto social como personal, tornando más perceptibles los significados profundos de la experiencia colectiva (COLOMBRES, 2004, p. 178). Pensemos aquí al musicar, sobre todo en sus aspectos estéticos, como un desplazamiento en el ámbito de lo extracotidiano sin que por ello deba perder significación social, ya que la producción de sentido ocurre en la propia dinámica actuante del cuerpo performático, dentro del cual sobresale el artista, pero que no se reduce sólo a él.

Esta idea de ritual en el espacio social, que podemos llamar también ocasión musical (HERNDON Y MCLEOD, 1979; CAMACHO, 2011), en tanto "acontecimiento inestable" (FRITH, 2014, p.358), nos provee incluso de una nueva denominación del fenómeno a estudiar, si es que quisiéramos resistimos al neologismo de Small. Aunque esto no es lo importante, sino tener presente que la música no es un objeto ni un guión, situación muy vislumbrada en lo conceptual pero ausente en la práctica historiográfica. Del mismo modo que el sujeto no es personalidad, sino persona, ya que la ocasión musical conlleva el cuerpo del actuante, del músico -cantante, instrumentista, productor- y del mismo modo incluye la corporeidad de todo el colectivo que participa, con mayor o menor intensidad, del musicar. El ritual -o mejor, la confluencia de rituales específicosaglutina los diversos roles en torno a la música que incluyen no sólo la producción en sí, sino la recepción y la circulación (COLOMBRES, 2004, p. 66), que adquieren formas específicas que son también históricas.

El carácter corporeizado del musicar nos lleva también a considerar lo que Simon Reynolds estima una cualidad física, en tanto vincula el ritual con el baile. El apelar al cuerpo no vuelve a la música menos ligada a lo racional. Al contrario, justamente el carácter físico de la performance musical que la vincula inextricablemente con el ritual, "disuelve la dicotomía entre cuerpo y mente, entre música "seria" para escuchar en casa y música "estúpida" para la pista de baile; hace que la mente baile y el cuerpo piense" (REYNOLDS, 2010, p. 180). La idea de que los bailarines "escuchan" con el cuerpo es un rasgo específico de las músicas del mundo popular subalterno, llámense polca, saltarello, pasacalle, fandango, huayno, bunde, mapalé, trance o dubstep. Aparece aquí con énfasis la estrecha relación entre sonido, escucha y cuerpo, que nos invita a salir de todo modelo objetual y autónomo. Si en la música popular "el cuerpo entero se vuelve oído" (REYNOLDS, 2010, p. 180) el medio que envuelve al cuerpo en el ritual del musicar es justamente el sonido que permite establecer una relación dialógica multidireccional, en tanto que son "expresiones de individualidad en una labor en conjunto" (QUINTERO RIVERA, 2009, p. 98). Entre los cuerpos, entre los músicos y los bailarines, entre el público -ya sea que participe más o menos activamente del ritual-, y entre los instrumentos y los cuerpos actuantes y danzantes. 
Si el cuerpo es parte del musicar, o mejor, si el performer construye sentido (COOK, 2011) y por lo tanto subjetiva la música en la ocasión musical social, potenciando lo colectivo de la acción, podemos pasar a proponer que la música y el musicar son transitoriamente la misma cosa, de forma tal que la música, sobre todo pero no sólo la del mundo popular subalterno, adquiere así las cualidades de lo móvil, cambiante, vivo, es decir, lo dinámico.

Podemos pensar que la forma en que el cuerpo habita la ocasión musical se acerca a las formas rituales en que la performance adquiere el carácter de trance, que se enlaza con las raíces de las prácticas religiosas precristianas en Europa y de las culturas matriciales americanas o animistas afroamericanas. El trance es posesión a través del ritual colectivo en donde cuerpo y sonido adquieren un rol protagónico. En esto descubriremos un aspecto muy ligado a lo que podemos considerar lo popular, en cuanto a un colectivo social poblado de diferencias y contrastes (QUINTERO RIVERA, 2009, p. 97).

Este carácter heteróclito del trance y el ritual social participa de una "naturaleza performativa de las identidades diferenciales" (BHABHA, 2013, p. 264) que fluctúan entre espacios sociales dinámicos, que se rehacen continua y contingentemente, y en el que habitan reivindicaciones múltiples, diversas, superpuestas e incluso contradictorias, como son en sí mismos los sectores populares y subalternos. Es una condición que nos permite densificar el concepto de musicar, proveyendo de cierta dimensión analítica que evita el "armonicocentrismo" y el "centrismo notacional". Aquí las discrepancias participatorias propuestas por Charles Keil como parte de su groovología se hacen particularmente relevantes:

El poder de la música reside en sus discrepancias participatorias, las cuales pertenecen básicamente a dos categorías: procesual y textural. Para poder producir una implicación personal y ser socialmente valiosa, la música ha de ir "a destiempo" y estar "desafinada" (KEIL, 2001, p. 261)

Es decir que en la música considerada musicar, ocasión musical en el ritual social, de carácter integral aunque inestable y dinámica, lo definitorio no es la configuración melódica ni la estructura armónica, sino la materialidad sonora que emerge de la trama de inflexiones y articulaciones dialógicas, el tejido del ritmo que dependerá a su vez de variantes en el tono y el timbre, desvíos entre los participantes y, con respecto al pulso, variantes mínimas o explícitas en la emisión de la voz o de los instrumentos. En definitiva, lo que desde nuestras limitaciones formativas llamamos "timbre" y "textura", y que justamente han recibido esos nombres tan poco elocuentes, que deben tanto a otras dimensiones que no son musicales, porque fueron despreciados por el pensamiento musical afirmativo de la modernidad al considerarlos elementos disruptivos, "ruidos" a canalizar (ATTALI, 2011). Que reciban ese tratamiento marginal en la teoría e historiografía y no se encuentren representados con claridad en el lenguaje "es evidencia, pienso, de su poder participatorio original y activo" (KEIL, 2001, p. 261). Precisamente esta condición contenciosa y cuasi contrahegemónica que implica la participación actuante de los cuerpos dialógicos, es todo un manifiesto de la necesidad de una nueva epistemología, ya que 
solo "si el momento de la performance es considerado como un acto potencial de composición, podrá emerger una perspectiva diferente"24 (MIDDLETON, 1990, p. 53).

La actuación es así un concepto, no la decodificación ni el subproducto de la circulación de una obra musical idealizada. En este cambio de estatuto que conlleva pasar de música a musicar, se da un movimiento que se aleja del énfasis en la "música per se" (HERNDON Y MCLEOD, 1979, p. 26) y nos revela lo inseparable del aspecto social que toda actividad musical posee. El musicar por lo tanto no se trata, bajo ningún concepto, de un medio para interpretar un texto autónomo, sino que es lo opuesto: algo "no-textual" (FRI$\mathrm{TH}, 2014$, p. 359) que adquiere significación en la integralidad del ritual social (ESCOBAR, 1991), y valor en base a las discrepancias que producen los participantes en el sonido.

\section{Del nomadismo al mestizaje}

La circulación de las músicas aparecen íntimamente relacionadas con la condición de nomadismo, que es a un tiempo de los seres y de los sonidos que habitan el mundo popular subalterno, y configuran esa voz que podía constituir la oportunidad de los excluidos para presentar sus propias ideas (BURKE, 2014, pp. 288-290). Considerar una equivalencia entre los sujetos musicales y la música, hace que la condición de los primeros sea parte de la definición de la segunda. Esto nos lleva a buscar el nomadismo en las músicas. Este nomadismo sonoro, este interés de las prácticas populares por las transiciones y los pasajes, identificación con lo diverso y múltiple, nos hace considerar la presencia de un carácter mestizo (como conceptualización) en toda la música del mundo popular subalterno. Si se piensa que el nómada en su periplo es potencialmente mestizo, pues conlleva un anuncio del mestizaje al atravesar los límites, las fronteras de la territorialización; lo que se nos revela cuando observamos las prácticas populares es que el mestizo no puede sino ser nómada, porque no hay nomadismo sin mestizaje (LAPLANTINE Y NOUSS, 2007). Esto está presente con mucha evidencia en las músicas del caminar y peregrinar, tan presentes en la historia profunda de América y Europa. Si por un lado ponen en cuestión o invierten las categorías de la historiografía -y por eso son producidas como inexistentes- podemos ver también que en la materialidad del sonido y su misma producción caminante, confluyen prácticas de diferentes localizaciones y sujetos históricos, y por lo tanto son habitadas por un mestizaje intrínseco, que es su misma condición de posibilidad. Este carácter transicional que obtura cualquier discusión sobre los orígenes, haciéndola obsoleta, aparece especialmente en las músicas americanas del tiempo colonial. Por ejemplo la habitual pregunta por la 'negrilla' o villancico de negro, sobre su lugar de origen en tanto big-bang se revela estéril, derivando en las disputas superficiales y eternas que son tan comunes tanto en la atribución autoral como en la patrimonialización folklórica: ¿de dónde es la diablada, de Oruro, de Puno, de la Tirana? ¿No es más interesante indagar sobre las conexiones históricas de estas ocasiones, sus puntos de contacto y su diversidad polifónica que les otorgan una identidad múltiple? 
¿Hay un lado del Atlántico en el cual ubicar a Manuel de Zumaya? ¿Cuánto mejor suena el tango una vez que se saldó, con corrección política más que historiográfica, la nacionalidad de Gardel? ¿De verdad vamos a seguir pensando que el árbol de Cucaña del carnaval de lquitos es una copia del rito arbóreo europeo? Y de ser así ¿En qué mejora todo esto nuestro conocimiento de las ocasiones musicales latinoamericanas?

La condición de nomadismo que aquí invocamos no implica en absoluto una pretensión de intervenir en la auto-percepeción de los sujetos populares en relación con su locus. Es una condición histórica de las músicas, del musicar, del hacer sonoro de esos sujetos, más allá de su ligazón duradera o efímera con un punto espacial específico. Los vínculos territoriales que surgen de las conceptualizaciones "emic" pueden (y deben) ser historizados. Y esas historias, por regla general, arrojarán vínculos movedizos, nómadas, transculturales. Carnavalizando la estrechez con que el folklore ha producido una territorialización forzosa de las culturas populares, aspecto funcional al despliegue afirmativo de la falsa universalidad (es decir colonialidad) de la musicología histórica.

Poder saltar sobre las fronteras que nos imponen estas preguntas es la real potencia del mestizaje en tanto pensamiento, que nos abre la puerta a nociones mucho más fecundas como Caribe Afroandaluz (GRIEGO, 2002) Atlántico Negro (GILROY, 1993) o cruce del Atlántico en dos sentidos (BERNAND, 2014). Así el mestizaje se vuelve un modo de pensar paradojalmente desracializado, aunque surge a partir de la redención de un término acuñado racialmente para el sometimiento y el despojo. Una palabra que ha recibido todos los tipos de manoseos, utilizaciones, violencias y maltratos imaginables, en consonancia con aquellos seres a los que describió y describe: los pardos, los moros, los impuros, los intermedios, los "del montón", que son también sin nombre, como los músicos históricos del mundo popular subalterno. El mestizaje disuelve toda potencia residual de la noción de autenticidad. Y lo hace mediante la estrategia de la cimarronería y el camuflaje: con la evasión, eludiendo los contrastes duros, mediante la ambigüedad, la incompletud, lo informe, lo contradictorio a partir de la recreación y la creación plurisubjetiva y pluritemporal.

Ahora bien, así como para la Modernidad territorio y armonía son dos elementos altamente vinculados e imprescindibles para pensar la dominación, situación definitoria del mundo popular subalterno, el mestizaje es también la cancelación de la armonía, entendida en su doble juego de lógica sonora y de consenso social. Porque el nomadismo no solo pone en cuestión la noción de territorio, sino también la de desplazamiento en tanto estrategia sonora: el movimiento mestizo del nómada es permanente y no conoce destinos; por lo tanto si desplazarse es ir de un lugar a otro, como ocurre en la forma tonal de la obra/objeto de la musicología, no hay desplazamiento en la práctica nómada y mestiza de la música popular. A diferencia de ésta, la música tonal culta es narrativa y derivada de la concepción teatral propia del mercado del espectáculo moderno (Small, 1989). Eso hace que la ópera "barroca" no sea popular -a pesar de lo que pensaba Gramsci- y una canción mulata, aparentemente repetitiva que se intensifica en su heterogeneidad dialógica, sí lo sea. La música nómada no se dirige a ninguna parte. Pero ella y quien la actúa saben que van, y por eso, son en sí mismos la circulación permanente en el espacio social. 
El mestizaje es conflictivo, litigante. Es una especie que no resuelve sus contradicciones y mantiene, dinámica e inestable, su heteronomía. Por eso las manifestaciones de la música popular no pueden entenderse como bienes - pues no son cosas ni objetos- o saberes -ya que son más que eso, ocasiones y rituales- que la historiografía afirmativa ha buscado hacer que pertenezcan al pueblo o, aún peor, que éste haga usufructo de ellos (VEGA, 1944). Por tanto la música popular es un espacio de disputa de sentido. Pensarla escindida, en oposición frontal a la cultura oficial, es reproducir los sesgos de estratificación y dominocentrismo. Porque así como el juglar nómada y el ministril indígena atraviesan las fronteras y se instalan en la corte o en la catedral "blanca" para introducir el ruido en el musicar, el espacio que configura la música popular tampoco pertenece al pueblo. Es moldeado y conformado de forma ambigua y heterogénea por los deseos, intereses y emociones de ese colectivo tan heteróclito que son las clases populares, pero está igualmente atravesado, regulado, intervenido y observado, constantemente, por los sectores hegemónicos. Al punto que, como revelaron Bajtín, Burke, Hall o Bernand, no podemos concebir lo popular por fuera de la estratificación que proponen los sectores dominantes.

Es una litigiosidad en la cual la música, como parte de la cultura popular, se vale de estrategias igualmente heterogéneas y mestizas: la sonoridad grotesca, el ruido que opaca la forma, las texturas y sonidos disruptivos. Músicas subversivas que se camuflan y cimarronean entre las lógicas constructivas de la música culta, el cruce incongruente de géneros, tradiciones o formatos, la evasión de las fronteras pretendidamente estilísticas y étnicas, entre tantas otras estrategias que evitan la confrontación directa y problematizan o cuestionan de manera elíptica o satírica.

\section{La potencia transmoderna de lo transcultural}

La cualidad de circulación social que planteamos más arriba refiere además a la potencialidad de establecer vínculos como característica de las músicas del mundo popular subalterno. La contradicción, lo liminal, lo deforme, lo no terminado, lo ambiguo, lo camuflado, son formas de lo popular que se exhiben continuas y aparecen tanto en la cultura popular europea como en la de los territorios coloniales sometidos por occidente. Este es el sentido extensivo que hace que las manifestaciones tan diversas y contrastantes de mundos muy dispersos puedan confluir en la noción del Mundo Popular Subalterno. Mundo de la inversión carnavalesca, que ofrece esa segunda vida del pueblo (BAJTíN, 2005) y que también aparece en el Mundo al Revés del universo profético incaico, que en crónicas mestizas, como las de Guaman Poma, introducen un elemento disruptivo dentro del orden colonial (CUSICANQUI, 2010). Esta es la continuidad transcultural de las músicas del mundo popular subalterno. Algo muy diferente a la continuidad folklórica que procede de la territorialización y el folk-market. La continuidad transcultural emerge de la desterritorialización forzosa de los colectivos dominados y revierte su signo introduciendo un sentido programático de la mixtura, el sancocho (QUINTERO RIVERA, 2005) y lo mestizo. La continuidad transcultural se erige en una 
posición que reclama reabrir la discusión sobre el sentido de la totalidad en un sistema-mundo (CASTRO-GÓMEZ, 1999) que el posmodernismo se ufanó de haber clausurado con la cancelación de los grandes relatos. Mientras disciplinas potencialmente críticas continúen por la senda de la fragmentación y el multiculturalismo, sus muchos e imprescindibles aportes no penetrarán en la afirmatividad de la historiografía musical.

La transculturación, como posibilidad de pensar las relaciones entre vertientes culturales conflictivas y distantes, pero además como proceso dinámico, es decir, de permanente mutación histórica, aparece como una interesante explicación desde el sur frente a la globalización. Al expresar la condición transitoria de la mezcla, la transculturación es parte de lo mestizo, ch'ixi y contencioso (CUSICANQUI, 2015) puesto que "no se centra solo en la propia identidad, porque esa identidad misma está cuestionada. Por definción, es una identidad en crisis. Se realiza en la polaridad identidad-alteridad" (PODETTI, 2004, p. 4). Frente a la fusión híbrida que propone la globalización, un multiculturalismo que sólo legitima aún más la monocultura de la colonialidad, la transculturación es un resguardo contra la fijación racializada que cuestiona precisamente esa -y cualquier otra- dominación cultural.

Pero estas consideraciones sobre la localización en el cuerpo y los sujetos, el mestizaje y nomadismo, la circulación conflictiva entre espacios sociales, la integralidad de las ocasiones musicales, la centralidad de la materialidad sonora en la música del mundo popular subalterno, nos impulsan a que reconsideremos nuestras metodologías y formatos de presentación, narración y enseñanza de la historiografía musical.

Nos gustaría pensar que estas dimensiones, estos indicadores que presentan la situación contenciosa y ch'ixi de las prácticas del mundo popular subalterno, pueden aportar a la configuración de lo que quisiéramos llamar una perspectiva transmoderna de una historiografía popular de las músicas. Un camino al abordaje en relación conjunta y crítica de todas las manifestaciones sonoras presentes en la sociedad, enriqueciendo y profundizando en las indagaciones y explicaciones de sus múltiples y conflictivas dimensiones históricas. Que habilite la posibilidad de comprender las músicas, sobre todo las latinoamericanas, como géneros de intersección (FORNARO, 2010) en espacios específicos de realización para músicas que comparten procedimientos y ancestros (BERNAND, 2014). Una perspectiva que además, y fundamentalmente, pueda pasar a las aulas y contribuir a densificar lo que a todas luces sigue constituyendo una de las áreas más conservadoras del conocimiento musical.

\section{Referencias bibliográficas}

Attali, J. (2011). Ruidos: Ensayo sobre la economía política de la música. México: Siglo XXI.

Bajtín, M. (2005). La cultura popular en la Edad Media y en el Renacimiento: El contexto de François Rabelais. Madrid: Alianza Editorial.

Beckles Willson, R. (2009). "Music Theory”, en Harper-Scott, J. P. E y Samson, J. An Introduction to Music Studies, Cambridge University Press. 
Bermúdez, E. (1982). La pobreza del positivismo. https://www.academia. edu/33884388/La_pobreza_del_positivismo_el_quehacer_musicologico_en_ Am\%C3\%A9rica_Latina

Bernand, C. (2014). “Identificaciones: músicas mestizas, músicas populares y contracultura en América (siglos XVI-XIX)". Historia Critica No. 54, Bogotá, septiembre - diciembre. ISSN 0121-1617, pp. 21-48

Bhabha, H. K. (2013). El lugar de la cultura. Buenos Aires: Ediciones Manantial.

Bieletto, N. (2016). Lo inaudible en el estudio histórico de la música popular. Texto de reflexión crítica. Resonancias, vol. 20 (38), 11-35.

Blum, S., Bohlman, P. V., \& Neuman, D. M. (1993). Ethnomusicology and modern music history. University of Illinois Press

Burke, P. (2014). La cultura popular en la Europa moderna. Madrid: Alianza Editorial.

Cabral, A. (2013). Nacionalismo y cultura. Barcelona: Bellaterra.

Camacho Díaz, G. (2011). Del oratorio al fandango: la subversión del orden social. En Aguilera, M. O. (2011). Las músicas que nos dieron patria: Músicas regionales en las luchas de independencia y revolución. Programa de Desarrollo Cultural Regional de Tierra Caliente.

Cannova, M. P. (2008). "Aquello que una presencia puede ocultar". Clang, n², pp-3844. http://sedici.unlp.edu.ar/handle/10915/49212

Cano, R. L., y Sans, J. F. (2011). Música popular y juicios de valor: Una reflexión desde América Latina. Caracas: Fundación Celarg

Carr, E. H. (2006). ¿Qué es la historia? Barcelona: Ariel.

Castro-Gómez, S. (1999). Pensar (en) los intersticios: Teoría y práctica de la crítica poscolonial. Bogotá: Pontificia Universidad Javeriana

Chartier, R. (2007). La Historia o la lectura del tiempo. Barcelona: Gedisa.

Colombres, A. (2004). Teoría transcultural del arte. Hacia un pensamiento visual independiente. Buenos Aires: Del Sol.

Cook, N. (2001). De Madonna al canto gregoriano: Una muy breve introducción a la música. Madrid: Alianza. 
Cook, N. (2011). Music as Performance. En Clayton, M., Herbert, T., \& Middleton, R. (2012). The cultural study of music: A critical introduction. Routledge.

Cusicanqui, S. R. (2010). Ch'ixinakax utxiwa: Una reflexión sobre prácticas y discursos descolonizadores. Buenos Aires: Tinta Limón.

Cusicanqui, S. R. (2015). Sociología de la imagen: Miradas ch'ixi desde la historia andina. Buenos Aires: Tinta Limón.

Dahlhaus, C. (1997). Fundamentos de la historia de la música. Barcelona: Gedisa.

De Martino, E. (2008). El Folclore progresivo y otros ensayos. Museu d'Art Contemporani.

Dussel, E. (2006). 20 tesis de política. Buenos Aires: Siglo XXI.

Dussel, E. (2007). Política de la liberación. Historia mundial y crítica. México: Siglo XXI.

Eagleton, T. (2006). La estética como ideología. Madrid: Trotta.

Eckmeyer, M. (2014). “Entre la música de las esferas y la sordera del genio". La Plata: Actas del las

6as Jornadas de Investigación en Disciplinas Artísticas y Proyectuales. FBA-UNLP.

Ellis, K. (2009). “The sociology of music”, en Harper-Scott, J. P. E y Samson, J. An Introduction to Music Studies, Cambridge University Press.

Escobar, T. (1991). "El mito del Arte y el mito del Pueblo" en Acha, J., Colombres, A., \& Escobar, T. . Hacia una teoría americana del arte. Buenos Aires: Ed. del Sol.

Erlmann, V. (2004). Hearing cultures. Essays on sound, listening, and modernity. Oxford: Berg.

Fornaro Bordolli, M. (2010). “De improviso: el canto payadoresco, expresión de origen hispano en el área rioplatense" en Recasens Barberà, A. (comp.) A tres Bandas: mestizaje, sincretismo e hibridación en el espacio sonoro iberoamericano, Madrid: Akal.

Frith, S. (2006). "La industria de la música" en Frith, S., Straw, W., \& Street, J. La otra historia del rock: Aspectos clave del desarrollo de la música popular: Desde las nuevas tecnologías hasta la política y la globalización. Ediciones Robinbook. 
Frith, S. (2014) Ritos de la interpretación: Sobre el valor de la música popular Entornos. Buenos Aires: Paidós.

García Linera, A. (2018). "Este es un neoliberalismo zombie". Página/12, 20 de noviembre. Recuperado de https://www.pagina12.com.ar/156724-este-es-unneoliberalismo-zombie

Garramuño, F. (2007). Modernidades primitivas: Tango, samba y nación. Buenos Aires: Fondo de Cultura Económica.

Gilroy, P. (1993). Atlántico Negro. Modernidad y doble conciencia. Madrid: Akal

Goehr, L. (1992). The imaginary museum of musical works an essay in the philosophy of music. Oxford: Clarendon Press.

González, J. P., \& Rolle, C. (2005). Historia social de la música popular en Chile, 18901950. Santiago: Ediciones Universidad Católica de Chile.

González, J. P. (2008). Los estudios de música popular y la renovación de la musicología en América Latina: ¿La gallina o el huevo?. TRANS-Revista Transcultural de Música 12 (artículo 15).

González, J. P., Ohlsen, O. \& Rolle, C. (2009). Historia social de la música popular en Chile, 1950-1970. Santiago: Ediciones Universidad Católica de Chile.

Griego, A. G. (2002). El mar de los deseos. México: Siglo Veintiuno Editores.

Griego, A. G. (2006). Fandango. El ritual del mundo jarocho a través de los siglos. México: Consejo Nacional para la Cultura y las Artes, Dirección General de Vinculación Cultural.

Griffiths, P. (2009). Breve Historia de la Música Occidental. Madrid: Akal.

Grignon, C., \& Passeron, J. C. (1992). Lo culto y lo popular: Miserabilismo y populismo en sociología y en literatura. Madrid: Ediciones de La Piqueta.

Grosch, N. (2005). “¿Música popular en la galaxia Gutenberg? Un intento de reinterpretación desde la perspectiva de la historia de los medios", en: Música popular, exclusión/inclusión social y subjetividad en América Latina, (VI Congreso de la IASPM-AL),

Grosfoguel, R. (2014). “La descolonización de la economía política y los estudios poscoloniales: transmodernidad, pensamiento descolonial y colonialidad global" en Santos, B. de Sousa Epistemologías del Sur. Madrid: Akal 
Grout, D. J. (1980). Historia de la música occidental. Madrid: Alianza Editorial.

Herder, J. G. (1967). Sämtliche Werke (ed. de B. Suphan), 25, Hildesheim.

Herndon, M. y McLeod, N. (1979). Music as Culture. Indiana: Norwood Editions.

Hesmondhalgh, D., \& Negus, K. (2012). Popular music studies. UK: Hodder Education.

Hoppin, R. (2000). La música medieval. Madrid: Akal.

Johnson, B. (2018). "Problematising popular music history in the context of heritage and memory" en Baker, S., Strong, C., Istvandity, L., \& Cantillon, Z. The Routledge Companion to Popular Music History and Heritage. Routledge.

Jordán González, L., \& Smith, D. (2012, 02). How did popular music come to mean música popular? IASPM@Journal, 2(1-2), 19-33. doi:10.5429/2079-3871(2011)v2i1-2.3.

Keil, Ch. (2001). "Las discrepancias participatorias y el poder de la música” en Cruces, F. y otros (ed.) Las culturas musicales. Madrid: Ed. Trotta.

Kerman, J. (1985). Contemplating music: Challenges to musicology. Cambridge, Mass: Harvard University Press.

Kerman, J., Tomlinson, G., \& Kerman, V. (2015). Listen. New York: W. W. Norton \& Company.

Krugman, P. (2019). Contra los zombies. Barcelona: Crítica

Langer, S. K. (1957). Philosophy in a new key: A study of the symbolism of reason, rite and art. Harvard University Press.

Laplantine, F., y Nouss, A. (2007). Mestizajes: De Arcimboldo a zombi. Buenos Aires: Fondo de Cultura Económica.

Leach, E. E. (2009). "Popular Music", en Harper-Scott, J. P. E y Samson, J. An Introduction to Music Studies, Cambridge University Press.

Marcuse, H. (1967[1937]). Cultura y sociedad. Buenos Aires: Sur.

Martín-Barbero, J. (1991). De los medios a las mediaciones. Convenio Andrés Bello.

Michels, U. ([1985]1992). Atlas de música. Madrid: Alianza. 
Middleton, R. y Horn, D. (1981). “Preface. Folk or Popular? Distinctions, Influences, Continuities". Popular Music, 1, 1-2.

Middleton, R. (1990). Studying popular music. Berkshire: Open Univ. Press

Mignolo, W. (2009). "El lado más oscuro del Renacimiento" Universitas humanística no. 67 enero-junio

Miller, K. H. (2010). Segregating sound: Inventing folk and pop music in the age of Jim Crow. Duke Univ. Press.

Ochoa Gautier, A. M., (2011). El sonido y el largo siglo XX. Revista Número, 51.

Ochoa Gautier, A. M., (2014). Aurality: Listening and knowledge in nineteenth-century Colombia. Duke University Press.

Paraskevaídis, G. (1999). "La investigación musical en su laberinto", Conferencia de clausura del Primer Foro de Investigación, Universidad de los Andes, Santa Fe de Bogotá, 22 de octubre.

Parry, Ch. H. (1896). The Evolution of the Art of Music. Londres: Kegan Paul, Trench, Trübner \& Co.

Pelinski, R. A. (2000). Invitación a la etnomusicología: Quince fragmentos y un tango. Madrid: Akal Ediciones.

Pérez González, J. (2010). Las historias de la música en Hispanoamérica (1876-2000). Bogotá: Universidad Nacional de Colombia.

Podetti, R. (2004). "Mestizaje y transculturación: la propuesta latinoamericana de globalización", Comunicación presentada en el VI Corredor de las Ideas del Cono Sur, 11 al 13 de Marzo, Montevideo, Uruguay.

Quintero Rivera, A. (2005). ¡Salsa, sabor y control! sociología de la música "tropical". México: Siglo Veintiuno.

Quintero Rivera, A. (2009). Cuerpo y cultura: Las músicas "mulatas" y la subversión del baile. Madrid: Editorial Iberoamericana..

Raynor, H. (1986). Una historia social de la música. Desde la edad media hasta Beethoven. Madrid: Siglo XXI. 
Reder Carlson, J. D. (2013). “¿Una modernidad primitiva? Andrés Chazarreta, el folklore argentino y los medios masivos de comunicación". Letra. Imagen. Sonido L.I.S. Ciudad mediatizada Año IV, \# 9. Buenos Aires

Reynolds,S. (2010). Después del rock. Psicodelia, postpunk, electrónica y otras revoluciones inconclusas. Buenos Aires: Caja Negra Editora.

Rondón, V. (2016). Dossier: Música, historia e historiografía. Resonancias, vol. 20 (38), 9-10.

Rose, S. (2005) "Music in the Market-place" en Carter, T., Butt, J. (eds.) Cambridge History of Seventeenth Century Music, Cambridge University Press.

Santamaría Delgado, C. (2007). El bambuco, los saberes mestizos y la academia: Un análisis histórico de la persistencia de la colonialidad en los estudios musicales latinoamericanos. Latin American Music Review / Revista De Música Latinoamericana, 28(1), 1-23.

Santos, B. de Sousa (2014). Epistemologías del sur. Madrid: Perspectivas. Akal.

Santos, B. de Sousa (2018). Construyendo las Epistemologías del Sur - Para un pensamiento alternativo de alternativas. Buenos Aires: CLACSO

Scott, D. (2003). From the erotic to the demonic: On critical musicology. Oxford: Oxford University Press.

Scott, D. (2011). Sounds of the metropolis: The Nineteenth-century popular music revolution in London, New York, Paris, and Vienna. Oxford University Press.

Scott, D. (2014). "Invention and interpretation in popular music historiography". En Helms, D. y Phelps, T. (Hg.), Geschichte wird gemacht: zur Historiographie populärer Musik. Bielefeld: Transcript Verlag.

Scott, D. (2016). The Ashgate research companion to popular musicology. Routledge.

Selden Pratt, W. (1905). The history of music. New York: Schrimer

Shreffler, A. C. $(2003,10)$. Berlin Walls: Dahlhaus Knepler, and Ideologies of Music History. The Journal of Musicology, 20(4), 498-525. doi:10.1525/jm.2003.20.4.498

Small, C. (1989). Música, sociedad, educación: Un examen de la función de la música en las culturas occidentales, orientales y africanas, que estudia su influencia sobre la sociedad y sus usos en la educación. Madrid: Alianza Editorial. 
Small, C. (1998). Music of the common tongue: Survival and celebration in African American music. Hanover, NH: University Press of New England.

Small, C. (1999). El musicar: un ritual en el espacio social. Revista Transcultural de Música, núm 4

Stanley, G. (2001). "Historiography" en The New Grove Dictionary of Music and Musicians 2nd Ed. New York: Oxford University Press.

Sterne, J. (2012). The sound studies reader. Routledge.

Stobart, H. (2009). “World Musics" en Harper-Scott, J. P. E y Samson, J. An Introduction to Music Studies, Cambridge University Press.

Suárez Urtubey, P. (2007). Historia de la música. Buenos Aires: Claridad.

Taruskin, R. (2005). The Oxford history of western music; Volume 1: Music from the earliest notations to the sixteenth century. Oxford University Press.

The International Advisory Editors (2005). Can We Get Rid of the 'Popular' in Popular Music? A Virtual Symposium with Contributions from the International Advisory Editors of "Popular Music". Popular Music, 24(1), 133-145. Retrieved from http://www.jstor. org/stable/3877598

Treitler, L. (1991). The Politics of Reception: Tailoring the Present as Fulfilment of a Desired Past. Journal of the Royal Musical Association, 116(2), 280-298.

Vega, C. (1944). Panorama de la música popular argentina: Con un ensayo sobre la ciencia del folklore. Buenos Aires: Instituto Nacional de Musicología Carlos Vega.

Veyne, P. (1984). Cómo se escribe la historia ; Foucault revoluciona la historia. Madrid: Alianza Editorial.

Walker, M. E. (2020). Towards a Decolonized Music History Curriculum. Journal of Music History Pedagogy, vol. 10(1). 1-19.

Weisbard, E. (2008). Listen again: A momentary history of pop music. Duke University Press.

White, H. (2010). Metahistoria: La imaginación histórica en la Europa del siglo XIX. México: Fondo de Cultura Económica.

Wisnik, J. M. (2015). Sonido y sentido: Otra historia de la música. Buenos Aires: La Marca Editora. 